\title{
Obtenção de Biodiesel
}

Tebas, S. O. G. ${ }^{1^{*}}$; Pereira, A. F. ${ }^{2}$; da Silva. P. H. A. ${ }^{3}$; Pinheiro, P. F. ${ }^{4}$; Pinheiro, C. A. ${ }^{4}$; Barañano, A. G.

1 Graduando em Engenharia Química, Universidade Federal do Espirito Santo, Alegre, ES, Brasil. 2 Departamento de Química, Universidade Federal de Viçosa, Viçosa, MG, Brasil.

3 Departamento de Tecnologia de Alimentos, Universidade Federal de Viçosa, Viçosa, MG, Brasil.

4 Programa de Pós-Graduação em Agroquímica, Universidade Federal do Espírito Santo, Alegre, ES, Brasil. 5 Programa de Pós-Graduação em Engenharia Química, Universidade Federal do Espírito Santo, Alegre, ES, Brasil.

*e-mail: saulotebas@hotmail.com

\section{Resumo}

O biodiesel é um combustível renovável, fabricado na maioria das usinas a partir do óleo de soja por via metílica. Para a obtenção do biodiesel são necessários, principalmente, três reagentes: óleo ou gordura, catalisador e um álcool (metanol ou etanol, usualmente). A reação de transesterificação é a etapa da conversão do óleo ou gordura em ésteres de ácidos graxos que constitui o biodiesel. O subproduto da produção do biodiesel é o glicerol, usado principalmente na fabricação de sabonetes, cosméticos e fármacos. Na produção do biodiesel são usados catalisadores que podem ser de natureza alcalina, ácida ou enzimática. A proporção molar óleo vegetal ou gordura/álcool e a temperatura reacional influenciam de maneira significativa a reação de transesterificação. Na obtenção do biodiesel os métodos de separação, recuperação e purificação estão diretamente relacionadas à sua qualidade. Além disso, um biodiesel de qualidade aceitável deve apresentar limites de contaminantes satisfatórios, bom desempenho na queima, de modo a não comprometer a integridade do motor e a segurança no transporte, e estabilidade química durante o processo de estocagem.

\begin{abstract}
Biodiesel is a renewable fuel produced in most plants from soybean oil by methyl pathway. Fat or oil, catalyst and an alcohol (methanol or ethanol, usually) for obtaining biodiesel, especially three reagents are required. The transesterification reaction is the step of converting the oil or fat into fatty acid esters that constitute biodiesel. The byproduct of biodiesel production is glycerol, mainly used in the manufacture of soaps, cosmetics and pharmaceuticals. In the production of biodiesel catalysts which can be alkaline, acidic or enzymatic nature are used. The molar ratio of vegetable oil or fat/alcohol and temperature reaction influence significantly the transesterification reaction. In obtaining biodiesel separation methods, recovery and purification are directly related to its quality. In addition, a biodiesel acceptable quality limits must present satisfactory contaminants, good performance in burning, so as not to compromise the integrity of the motor and transportation safety, and chemical stability during storage.
\end{abstract}

Keywords: transesterification of fats and oils, alcohols, catalysts, parameters of quality

\section{Introdução}

A aplicação de óleos vegetais como biocombustíveis teve seu marco em 1898, onde
Rudolf Diesel apresentou em uma Feira Mundial em Paris o funcionamento de um motor abastecido com óleo de amendoim de melhor eficiência do que os motores a vapor usados na época. No 
início do século $X X$, o óleo mineral chamado de óleo diesel em homenagem ao Rudolf Diesel tornou-se o combustível para o motor apresentado na referida feira, devido apresentarem melhores propriedades físicoquímicas e menor custo [1].

O uso de óleos vegetais em motores a diesel tem sido incentivado em todo o mundo, as ideias de Rudolf Diesel voltaram à tona e apresentam-se como uma proposta viável de energia renovável. Os problemas ambientais ocasionados pela grande emissão de poluentes devido à queima de combustíveis minerais, o aquecimento global, o custo elevado do petróleo e a importância do uso de energia renovável que seja menos agressiva ao homem e ao meio ambiente são os principais fatores responsáveis pela valorização e importância do biodiesel como fonte energia [2].

Apesar dos estudos anteriores ter apresentado resultados promissores quanto ao uso de biocombustíveis obtidos a partir de óleos vegetais, a mistura de biodiesel ao diesel fóssil teve início no Brasil em dezembro de 2004, em caráter autorizativo. A mistura de óleo diesel e biodiesel é chamada de "BX", onde " $B$ " indica a mistura e o " $X$ " à porcentagem em volume do biodiesel na mistura, onde B2 quer dizer que a mistura corresponde a $2 \%$ de biodiesel e $98 \%$ de óleo diesel, já uma mistura que tem $5 \%$ de biodiesel e $95 \%$ de óleo diesel é chamada de B5, e assim por diante, até o biodiesel puro B100 [3].

Em janeiro de 2008, entrou em vigor a mistura legalmente obrigatória de $2 \%$ (B2) [4]. Com o perceptível amadurecimento do mercado brasileiro, esse percentual foi ampliado pelo Conselho Nacional de Política Energética (CNPE) sucessivamente até atingir 8\% (B8) em março de 2016 [5].

O biodiesel é obtido por meio de uma reação química chamada de transesterificação ou por outros processos chamados de craqueamento ou esterificação.

$\mathrm{Na}$ verdade, o nome bio refere-se à fonte de uma das matérias-primas usada, que geralmente é um óleo vegetal, sendo o mais usado nas usinas o óleo de soja. Além desse, outros óleos vegetais vem sendo usados na produção de biodiesel, dentre eles destacam-se os óleos de girassol, mamona, pinhão manso, dendê (palma), babaçu e amendoim [6].

As gorduras também podem ser usadas na fabricação de biodiesel. O sebo bovino, a banha de porco, a gordura de frango e os óleos de peixes são exemplos de matéria-prima de origem animal que podem ser usadas na obtenção do biodiesel, o que reduz os custos com a matéria prima [7]. Os óleos vegetais e gorduras animais apresentam em sua composição os triacilglicerídeos, que são os tri-ésteres providos do glicerol (triálcool, conhecido também como propano1,2,3-triol) ligado a três ácidos carboxílicos de cadeia longa (ácidos graxos) [8].

A Figura 1 mostra as principais matérias-primas utilizadas para produção de biodiesel no Brasil. A soja é a cultura mais utilizada para fabricação de biodiesel.

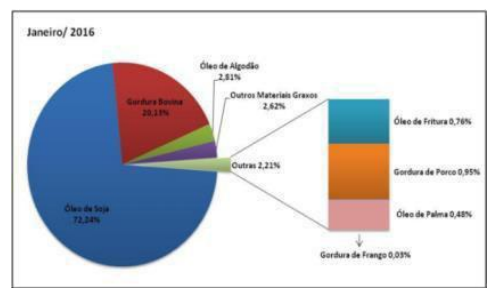

Figura 1: Matérias-primas utilizadas para produção de biodiesel no Brasil. Fonte: (ANP, 2016).

Os triacilgelicerídeos na presença de um álcool de cadeia curta, geralmente álcool etílico ou metílico, e de um catalisador (ácido, básico ou enzima) sofrem uma reação chamada de transesterificação, e como produto são obtidos ésteres de cadeia longa (etílicos ou metílicos) que compõem o biodiesel e o glicerol (subproduto) [9].

Os óleos vegetais apresentam alta viscosidade, por isso não apresentam bom desempenho nos motores, quando convertidos em seus respectivos ésteres (biodiesel) tornam-se viáveis como combustíveis. O biodiesel (mistura de ésteres) apresenta menor ponto de névoa, densidade e viscosidade que o óleo utilizado como matéria-prima, sendo que o poder calorífico permanece constante [10].

A reação de transesterificação, representada nas Figuras 2, é um termo geral usado para descrever uma importante classe de reações orgânicas, onde um éster é transformado em outro através da troca do resíduo 
alcoxila. Quando o éster original reage com um álcool, o processo de transesterificação é denominado alcoólise.

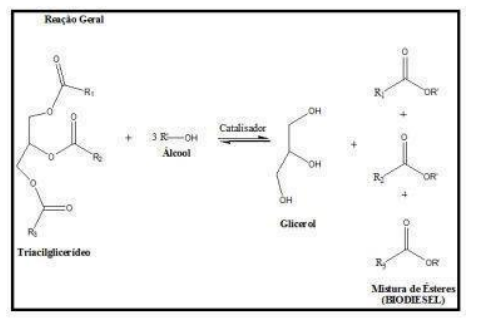

Figura 2: Reação geral de transesterificação.

A reação de transesterificação é reversível, por isso há a necessidade de se adicionar um catalisador, para acelerar a reação, e o álcool deve ser adicionado em excesso. Os dois fatores somados melhoram o rendimento da reação e permitem a separação do biodiesel do glicerol formado [11].

\subsection{Catalisadores usados na síntese do biodiesel}

Os catalisadores usados na reação de transesterificação (síntese do biodiesel) podem ser de ordem alcalina, ácida ou enzimática. A escolha do catalisador depende do tipo e da qualidade da matériaprima a ser utilizada. Em matérias-primas com alto índice de acidez, ou seja, elevados teores de ácidos graxos livres, o catalisador do tipo ácido é uma opção, por não apresentar restrições quanto às propriedades de acidez da matéria-prima, e como desvantagem, necessita de um maior tempo de reação quando comparado ao catalisador alcalino. Os óleos de frituras residuais apresentam elevado grau de oxidação, dessa forma são mais eficientes quando transesterificadas com catalisadores ácidos, como exemplo: o ácido sulfúrico pode ser usado como catalisador [12].

No caso da catálise alcalina, é necessário atentar para o teor de ácidos graxos livres presentes na matériaprima, bem como o teor de água. Esses fatores interferem negativamente no processo, já que consomem o catalisador, formando sabão, aumentam a viscosidade do produto final e dificultam a separação da glicerina. Os catalisadores alcalinos mais utilizados são os hidróxidos de sódio e potássio ( $\mathrm{NaOH}$ e $\mathrm{KOH})$, carbonatos e os alcóxidos como metóxido de sódio $\left(\mathrm{CH}_{3} \mathrm{ONa}\right)$ e metóxido de potássio $\left(\mathrm{CH}_{3} \mathrm{OK}\right)$ [13].
O principal catalisador utilizado em escala industrial é o metóxido de sódio, entretanto o seu uso necessita do uso de óleos neutros, com baixo teor de ácidos graxos livres e baixa umidade, para que não ocorra à saponificação ou neutralização entres os reagentes. $O$ metóxido de sódio pode ser obtido comercialmente em diferentes concentrações e puro, o que facilita a reação e aumenta o seu rendimento [12].

Os catalisadores podem ser homogêneos (dissolvem no meio reacional) ou heterogêneos (funcionam como adsorventes, são insolúveis no meio reacional). Os catalisadores heterogêneos são facilmente removidos por um simples processo de filtração, reduzindo assim a geração de efluentes, podem ser reutilizados e simplificam a purificação do biodiesel. Devido às inúmeras vantagens apresentadas por catalisadores heterogêneas várias pesquisas vêm sendo realizadas tendo como foco a descoberta desses materiais [10].

DABDOUB et al.[12] citam como catalisadores heterogêneos que vem sendo estudados na síntese do biodiesel: as resinas poliméricas de troca-iônica, membranas zeólitas, complexos metálicos, metais ativos em suportes sólidos, óxidos metálicos e enzimas do tipo lipases.

O catalisador considerado ideal ainda não foi relatado, mas para ter maior validade e aplicabilidade na indústria, esse catalisador deverá fazer parte de um processo ideal ou no mínimo "otimizado". Neste sentido, a utilização adequada do metóxido de sódio em um processo otimizado, em ciclo fechado, ainda não foi superada em termos de viabilidade técnica, energética ou econômica pelo uso de nenhum outro catalisador ou processo [14].

Os catalisadores químicos fornecerem altos níveis de conversões em triglicerídeos em curtos períodos de tempo. Mas esse tipo de catalisador apresenta algumas desvantagens, tais como: necessidade de grande energia térmica para ocorrência da reação, problemas com a recuperação do glicerol e a necessidade de um tratamento posterior ao processo para remoção do catalisador (ácido ou base) do produto, as águas de 
lavagem necessitam de um tratamento adequado e, por fim, a qualidade da matéria-prima com relação aos teores de ácidos graxos livres e umidade prejudicam severamente o rendimento da reação [14].

O processo de transesterificação enzimática consiste no processo de modificação lipídica catalisada pelas lipases, enzimas obtidas predominantemente de bactérias, leveduras e fungos. O processo, se otimizado, oferece inúmeras vantagens em relação ao processo químico, pois permite maior controle sobre a distribuição posicional dos ácidos graxos no produto final devido à seletividade das lipases. As lipases são conhecidas por terem a propensão a atuar mais efetivamente em moléculas de cadeia carbônica longa [12].

$\mathrm{Na}$ produção eficiente de biodiesel há uma grande necessidade por estabelecer protocolos de processos e parâmetros operacionais que permitam: utilizar qualquer matéria-prima independente da sua origem (gorduras animais ou óleos de qualquer grão ou fruto) através da: padronização da matéria-prima para empregar o catalisador escolhido de forma eficiente e satisfatória. Por exemplo, através do refino completo ou simplesmente pela neutralização e secagem dos lipídeos. No processo enzimático certos problemas como formação de sabão e neutralização podem ser reduzidos, além da possibilidade de obter-se os produtos, glicerina e biodiesel, em maior grau de pureza, e possibilidade do reuso do biocatalisador.

Verifica-se, ainda, que a via enzimática substitui os agressivos produtos usados como catalisadores na via química, propicia a reciclagem do catalisador, evita a contaminação do biodiesel, facilitando assim o processo de purificação. A principal limitação para a aplicação industrial do processo de transesterificação enzimática é ainda o alto custo das enzimas, tornando a substituição dos catalisadores químicos um grande desafio. Segundo RODRIGUES [15], o reuso da lipase é essencial sob o ponto de vista econômico, o que pode ocorrer com a utilização de lipases imobilizadas. É de grande importância a obtenção de um derivado imobilizado estável ativo e seletivo.
Vários trabalhos vêm sendo realizados com o intuito de contornar esse problema, incluindo a imobilização das lipases em suportes que permitam a reutilização do derivado imobilizado, as lípases imobilizadas mais estudadas foram a Candida antártica e a Termomyces lanuginosas. Contudo, tanto o rendimento como o tempo de reação ainda são desfavoráveis se comparados com o sistema de reação por catálisebásica para escala industrial [12]

\subsection{Etapas de produção do biodiesel}

Segundo COSTA [16], em uma planta de produção de biodiesel são envolvidas diversas operações unitárias. Além da reação de transesterificação, recuperação e purificação dos subprodutos e produtos finais. A Figura 3 representa um fluxograma de biodiesel em escala industrial, utilizando etanol ou metanol como fonte de álcool, e $\mathrm{NaOH}$ ou $\mathrm{KOH}$.

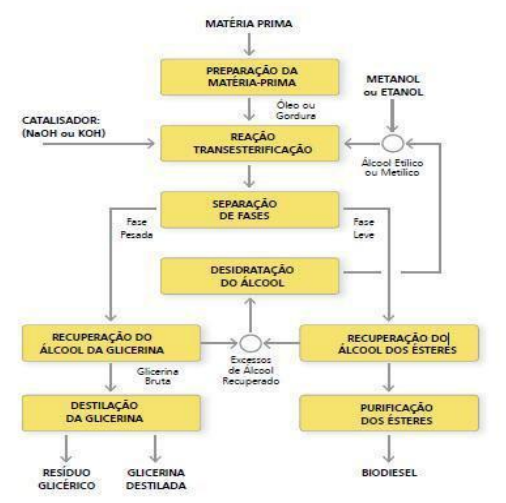

Figura 3: Fluxograma da produção industrial de biodiesel. Fonte:(EMBRAPA.,2016).

Os processos mais utilizados envolvem as etapas de transesterificação via catálise alcalina, processos contínuos com um ou dois reatores em série e as operações unitárias de separação, purificação e recuperação.

Utilizam-se reagentes com algumas características préestabelecidas, a fonte de álcool deve ser anidra e preferencialmente de baixo peso molecular, as fontes de triacilglicerol com baixa acidez e baixa umidade. E a reação deve ocorrer preferencialmente em pressão atmosférica e as temperaturas reacionais são próximas 
ao ponto de ebulição do álcool, a fim de reduzir o tempo de reação [1].

\section{Considerações finais}

As pesquisas visando encontrar métodos alternativos como fontes de energia renováveis são de grande importância, nesse sentido o biodiesel apresenta-se como uma promissora solução na diminuição do uso de combustíveis fósseis.

O Brasil se destaca na produção do Biodiesel, a matéria-prima usada, predominantemente, é o óleo de soja, outras oleaginosas vêm sendo estudadas. A via metílica ainda é a mais usada na produção do biodiesel. A descoberta de novos catalisadores para a obtenção do biodiesel é de grande importância, já que ainda não foi obtido um catalisador ideal.

\section{REFERÊNCIAS}

[1] RINALDI, R.; GARCIA, C. et. Al. Química Nova, São Paulo, v. 30, p. 1374-1380, 2007.

[2] LIMA, J. R. O. et al. Química Nova, v. 30, p. 600603 ,

2007.

[4] MOURA, B. S. Transesterificação alcalina de óleos vegetais para produção de biodiesel: avaliação técnica e econômica. 146f. Dissertação (Mestrado em Engenharia Química). Programa de Pós-Graduação em Engenharia Química. Instituto de Tecnologia, Universidade Federal do Rio de Janeiro, Seropédica, Rio de Janeiro, 2010.

[4] MOTA, C. J. A. et al. Química Nova, v.32, p 639648 , 2009.

[5] Ministério Minas e Energia, Brasília. Disponível em http://www.mme.gov.br/web/guest/paginainicial/outras-noticas/-

/asset publisher/32hLrOzMKwWb/content/cnpe-defineregras-para-as-misturas-de-biodiesel-b7-e-b8. Acesso em 23 Set. 2016.
[6] TAPANES, N. L. C. et al. Acta Scientiae \&

Technicae, v.1, p. 119-125, 2013.

[7] DELGADO, M. M. et al. Ciência \& Tecnologia:

FATEC-JB, v. 1, 2010. Suplemento.

[8] MERÇO, F. Química Nova na Escola, v. 32, p. 7883, 2010.

[9] MENEGHETTI, S. M. P. et al. Revista Virtual de Química, v. 5, p. 63-73, 2013.

[10] LÔBO, I. P. et al. Química Nova, v. 32, p. 15961608, 2009.

[11] GERIS, R. et al. Química Nova, v. 30, p. 13691373 ,

2007.

[12] DABDOUB M. J. et al. Química Nova, v. 32, p. 776-792, 2009.

[13] TAPANES, N. L. C. O. M. et al. Acta Scientiae \& Technicae, v. 1, p. 119-125, 2013. 2009.

[14] GOLDEMBERG, J.; GUARDABASSI, P., Bioprod. Bioref, $\quad \vee \quad 1, \quad$ p. 663-665, 2010

[15] RODRIGUES, R. C. Síntese de Biodisel através de tranesterificação enzimática de óleos vegetais catalizada por lipase imobilizada por ligação covalente multipontual. $183 \mathrm{f}$. Tese ( Doutorado em Engenharia Química), Programa de Pós-Graduação em Engenharia Química, Escola de Engenharia, Universidade Federal do Rio Grande do Sul, Porto Alegre, 2009.

[16] CostA, R. A. B. Estudo das eficiências de Operações e consumo de Energia em Plantas de Biodiesel. Dissertação( Mestrado em Engenharia Química), Programa de Pós-Graduação em Engenharia Química, Escola Politécnica, Universidade São Paulo, São Paulo, 2009.

[17] EMBRAPA - Plano Nacional de Agroenergia 20152016/Ministério da Agricultura, Pecuária e Abastecimento, Secretaria de Produção e Agroenergia. 2. ed. rev. - Brasília, DF : Embrapa Informação Tecnológica, 2016, $110 \mathrm{p}$. 